(2) Open Access Full Text Article

REVIEW

\title{
Long-term management of Alport syndrome in pediatric patients
}

This article was published in the following Dove Press journal:

Pediatric Health, Medicine and Therapeutics

3I May 2013

Number of times this article has been viewed

\section{Clifford E Kashtan}

Department of Pediatrics, Division of Nephrology, University of Minnesota Medical School, Minneapolis, MN, USA
Abstract: Alport syndrome, an important inherited cause of end-stage renal disease, has long been considered an untreatable disorder. That view is changing as a result of treatment studies in experimental animals and human populations. This review describes current management of Alport kidney disease, which is based on early diagnosis and institution of therapy with antagonists of the renin-angiotensin-aldosterone system.

Keywords: Alport syndrome, glomerular basement membrane, type IV collagen, familial hematuria

\section{Introduction}

The last three decades of the 20th century comprised a very fertile period for research on Alport syndrome. Milestone achievements during this period included identification of type IV collagen genes as the loci of mutations in patients with Alport syndrome and correlation of biochemical changes in basement membranes with the structural and symptomatic features of the Alport phenotype. More recently, an equally important development has been erosion of the longstanding view of Alport syndrome as an untreatable kidney disease.

For generations, nephrologists accepted that patients with Alport syndrome would inexorably progress to end-stage renal disease, with dialysis and renal transplantation as their only therapeutic options. The beginning of the end of this conventional wisdom can be traced to two factors, ie, the accrual of experimental and clinical data supporting the efficacy of inhibition of the renin-angiotensin-aldosterone system (RAAS) in slowing progression of chronic kidney diseases to end-stage renal disease and the establishment and exploitation of animal models of Alport syndrome enabling studies of therapeutic interventions, including RAAS inhibition. The results of these experiments have provided direction for clinical studies that have generated data suggesting that early treatment with RAAS inhibitors delays end-stage renal disease in patients with Alport syndrome. In addition, by demonstrating that the Alport nephropathy is not immutable, these promising initial steps have generated enthusiasm for pursuing even more successful treatments.

\section{Biochemistry and genetics}

Type IV collagen is the major structural constituent of basement membranes. Each of the six type IV collagen $\alpha$ chains, ( $\alpha 1[\mathrm{IV}]-\alpha 6[\mathrm{IV}])$, is encoded by a specific gene (COL4A1-COL4A6). The type IV collagen genes are arranged in pairs on three 
chromosomes: $C O L 4 A 1$ and $C O L 4 A 2$ are on chromosome 13; COL $4 A 3$ and COL $4 A 4$ are on chromosome 2; and COL $4 A 5$ and $C O L 4 A 6$ are on the $\mathrm{X}$ chromosome.

About $80 \%$ of people with Alport syndrome have X-linked disease due to mutations in the COL $4 A 5$ gene. Approximately $15 \%$ have autosomal-recessive disease due to mutations in both alleles of either $C O L 4 A 3$ or $C O L 4 A 4$. While rare families have autosomal-dominant Alport syndrome resulting from a single $C O L 4 A 3$ or $C O L 4 A 4$ mutation, heterozygous mutations in $C O L 4 A 3$ or $C O L 4 A 4$ typically are asymptomatic or cause thin basement membrane nephropathy, a disorder that is genetically related to Alport syndrome but usually has a benign outcome. A detailed discussion of the genetics of Alport syndrome and thin basement membrane nephropathy can be found on genereviews.org and in a recent review. ${ }^{1}$

Type IV collagen $\alpha$ chains associate into trimers that combine with each other to form open networks; these networks interact with laminin, nidogen, and heparan sulfate proteoglycans to form basement membranes. Mammalian tissues express three type IV collagen networks that differ on the basis of the composition of the trimers that comprise the networks. A network composed entirely of $\alpha$ (IV) and $\alpha 2$ (IV) chains is found in varying amounts in all basement membranes. A network consisting solely of $\alpha 3$ (IV), $\alpha 4(\mathrm{IV})$, and $\alpha 5$ (IV) chains is present in substantial amounts in glomerular basement membranes, some renal tubular basement membranes, and basement membranes of the cochlea and eye. A third network made up of $\alpha 5$ (IV) and $\alpha 6$ (IV) chains is present in the skin basement membrane and some renal tubular basement membranes.

The effect of most mutations in COL4A3, COL4A4, or $C O L 4 A 5$ is to prevent or impair deposition of the $\alpha 3 \alpha 4 \alpha 5$ (IV) network into basement membranes. This network is not required for ontogeny of the kidney, cochlea or eye; consequently, these organs are structurally and functionally normal at birth in people with Alport syndrome. The $\alpha 3 \alpha 4 \alpha 5$ (IV) network appears to be critical for maintaining the integrity of the mature basement membranes in which it resides, perhaps ameliorating the cumulative biomechanical stresses resulting from pulsatile blood flow (glomeruli), organ of Corti displacement by sound waves (cochlea), and changes in curvature of the lens with accommodation (eye).

\section{Clinical aspects}

The Alport nephropathy progresses through a predictable series of stages that are defined by simple laboratory tests (Table 1; a similar staging system was recently described ${ }^{2}$ ). All patients with progressive Alport syndrome (see Table 2) proceed through these stages, although the onset and duration
Table I Stages of the Alport nephropathy based on simple laboratory evaluations

\begin{tabular}{|c|c|c|c|c|}
\hline \multicolumn{5}{|c|}{ Stages of the Alport nephropathy } \\
\hline Stage I & Hematuria & & & \\
\hline Stage 2 & Microalbuminuria & & & \\
\hline Stage 3 & & Proteinuria & & \\
\hline \multirow[t]{2}{*}{ Stage 4} & & & Declining & \\
\hline & & & GFR & \\
\hline Stage 5 & & & & ESRD \\
\hline
\end{tabular}

Abbreviations: GFR, glomerular filtration rate; ESRD, end-stage renal disease.

of each stage vary according to genotype. Among males with $\mathrm{X}$-linked Alport syndrome, those with deletion and nonsense mutations progress through these stages relatively rapidly, while those with missense mutations often progress at a slower pace. ${ }^{3}$ In females with X-linked Alport syndrome, the pattern of $\mathrm{X}$ inactivation appears to have a greater impact on rate of progression than the mutation genotype. ${ }^{4}$

Stage 1 of the Alport nephropathy begins at birth and consists of persistent microscopic hematuria; some patients have intermittent to nearly continuous gross hematuria, and others, especially females with X-linked disease, have intermittent microscopic hematuria. In Stage 1, the urine dipstick is negative for any other abnormalities. The duration of stage 1 is a few years to a few decades, depending on gender and genotype. Stage 1 is associated with predominantly thin and presumably fragile glomerular basement membranes.

The transition from stage 1 to stage 2 occurs with the onset of microalbuminuria, arbitrarily defined as a microalbumin-creatinine ratio greater than $30 \mathrm{mg} / \mathrm{g}$. The urine dipstick typically remains negative for albumin until the microalbumin-creatinine ratio increases to about $200 \mathrm{mg} / \mathrm{g}$ creatinine. Once there is overt proteinuria, defined as a urine dipstick reading for protein of $1+$ or greater or a urine protein-creatinine ratio greater than $0.2 \mathrm{mg} / \mathrm{mg}$, the patient has moved into stage 3 . The histological correlates of stages 2 and 3 include thickening and lamellation of glomerular basement membranes associated with effacement of visceral epithelial cell (podocyte) foot processes.

Glomerular filtration rate begins to decline in stage 4 . Glomerular filtration rate, as estimated by creatinine clearance,

Table 2 Lifetime risk of ESRD in subjects with Alport syndrome based on genetic type and gender

\begin{tabular}{ll}
\hline Alport syndrome: lifetime risk of ESRD & \\
X-linked & \\
Male & $100 \%$ \\
Female & $30 \%$ \\
Autosomal recessive & $100 \%$ \\
Autosomal dominant & $\sim 100 \%$ \\
\hline
\end{tabular}

Note: *ESRD may be delayed until age 60 or greater in patients with autosomal dominant Alport syndrome.

Abbreviation: ESRD, end-stage renal disease. 


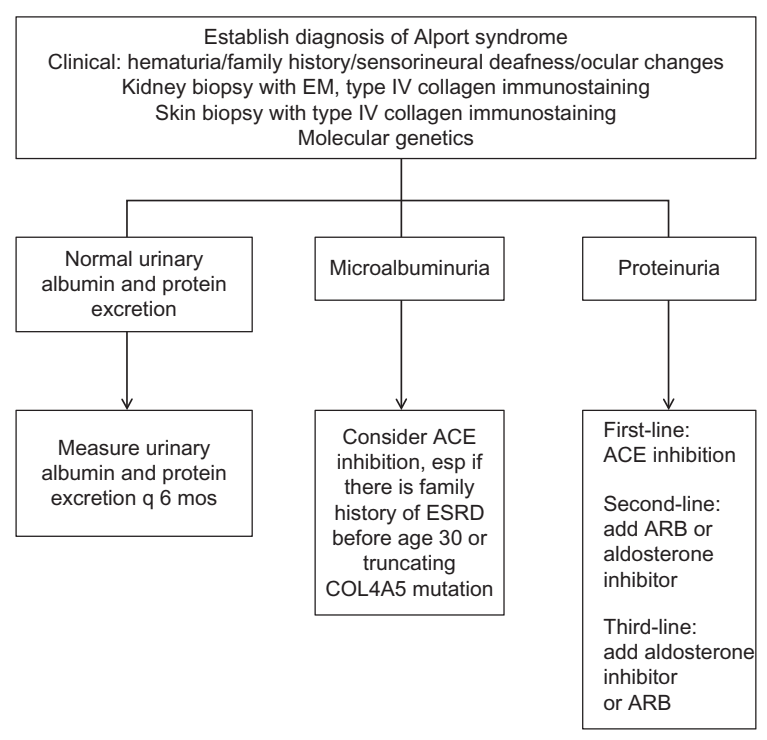

Figure I A treatment algorithm for patients with Alport syndrome. According to this algorithm, all patients with Alport syndrome should be considered candidates for intervention as soon as they exhibit overt proteinuria, regardless of family history, gender or genotype. At this time the primary intervention is an ACE inhibitor, with escalation of treatment according to response. ${ }^{8}$

Abbreviations: $\mathrm{EM}$, electron microscopy; $\mathrm{ACE}$, angiotensin-converting enzyme; $A R B$, angiotensin receptor blocker; ESRD, end-stage renal disease.

is inversely correlated with cortical interstitial volume fraction, a measure of fibrosis of the renal interstitium. ${ }^{5}$ Creatinine clearance is maintained in the normal range until cortical interstitial fibrosis increases above the upper limit of the normal range, suggesting that suppression of renal interstitial fibrosis will protect kidney function in Alport patients. In boys with Alport syndrome, cortical interstitial volume fraction is usually normal through the first 10 years of life but then begins to increase. ${ }^{5}$ Therefore, intervention to suppress interstitial fibrosis may have the greatest impact if initiated during childhood.

Overall, about $50 \%$ of males with X-linked Alport syndrome reach stage 5 end-stage renal disease by age 25 years, $90 \%$ by age 40 years, and nearly $100 \%$ by age 60 years. ${ }^{3}$ The timing of stage 5 in men with X-linked Alport syndrome is heavily influenced by COL4A5 genotype (Table 3 ). Those with more severe genotypes may derive the greatest benefit from effective early intervention. Approximately $30 \%$ of females with X-linked Alport syndrome reach end-stage renal disease by age 80 years. ${ }^{4}$

Sensorineural deafness is a significant problem for many children and adolescents with Alport syndrome, especially but not exclusively affected boys. In boys, high-frequency hearing loss is often detectable on audiometry by age 6-7 years. Hearing loss gradually spreads into the frequency range of conversational speech, leading to a need for amplification by late childhood or early adolescence in many affected boys.
Table 3 Effect of COL4A5 genotype on timing of ESRD in males with X-linked Alport syndrome

\begin{tabular}{lll}
\hline Mutation type & $\begin{array}{l}\text { Probability of } \\
\text { ESRD before } \\
\text { age 30 }\end{array}$ & $\begin{array}{l}\text { Age at which 50\% } \\
\text { have reached ESRD } \\
\text { (yrs) }\end{array}$ \\
\hline $\begin{array}{l}\text { Deletions and other large } \\
\text { rearrangements }\end{array}$ & $90 \%$ & 20 \\
$\begin{array}{l}\text { Nonsense mutations } \\
\text { Frameshift mutations }\end{array}$ & $70 \%$ & 25 \\
\hline Splice-site mutations & $50 \%$ & 30 \\
\hline Missense mutations & &
\end{tabular}

Abbreviation: ESRD, end-stage renal disease.

Fortunately, speech discrimination is usually well preserved and the hearing deficit reaches a plateau at which amplification is still effective. Consequently, Alport patients with hearing loss achieve good outcomes with hearing aids.

Unfortunately, some children with Alport syndrome and hearing loss are not identified until they fail screening examinations or show poor school performance. Adolescents may fear being stigmatized by use of hearing aids, and may resist wearing them. The cost of hearing aids may stress family finances or may be beyond the family's means.

Several specific ocular anomalies can occur in patients with Alport syndrome, particularly males, including anterior lenticonus, a peripheral and perimacular retinopathy, and rarely, posterior polymorphous dystrophy. These anomalies rarely result in disturbance of visual acuity during childhood and adolescence. Some patients with anterior lenticonus develop refractive errors in late adolescence or adulthood; cataract removal is necessary in some adult patients.

\section{Diagnosis}

Early and accurate diagnosis is a prerequisite for early intervention in Alport syndrome. The diagnostic approach in children with hematuria is based on careful evaluation of clinical features and family history, supplemented by tissue biopsy and molecular genetic analysis, as discussed in recent reviews. ${ }^{1,6}$ Availability of diagnostic methods varies geographically; at present a single algorithm is not feasible.

Alport syndrome should be considered in any child with persistent hematuria. A family history of hematuria, with or without renal failure, should increase suspicion of Alport syndrome. However, absence of such family history does not exclude the diagnosis, since about $10 \%$ of children with Alport syndrome have de novo mutations, and family history of renal failure is typically negative in children with 
autosomal recessive Alport syndrome. Hematuria is present in Alport syndrome long before hearing loss and ocular abnormalities are detectable. Therefore, while the presence of characteristic sensorineural deafness or ocular changes in a child with hematuria increases suspicion for Alport syndrome, normal hearing and eye examinations do not serve to rule out Alport syndrome.

A suspected diagnosis of Alport syndrome can be confirmed by biopsy of the kidney or skin. Complete evaluation of kidney biopsy material requires light, immunofluorescence, and electron microscopy. Diagnosis of Alport syndrome is made on the basis of pathognomonic changes in glomerular basement membrane ultrastructure and abnormalities of renal basement membrane expression of type IV collagen chains. ${ }^{7}$ The X-linked form of Alport syndrome can also be diagnosed by immunostaining of skin biopsy specimens for type IV collagen.

Clinicians in many but not all parts of the world now have access to molecular genetic testing for diagnosis of Alport syndrome through commercial laboratories or laboratories associated with medical institutions. Such testing offers high rates of diagnostic accuracy, particularly for X-linked Alport syndrome. Insurance coverage for genetic testing varies widely, so that the availability of testing does not ensure accessibility.

\section{Management}

Current clinical practice recommendations for delaying endstage renal disease in patients with Alport syndrome focus on early introduction of RAAS inhibitors to suppress urinary protein excretion. ${ }^{8}$ The focus on RAAS inhibition is based on experimental and clinical evidence as well as practical considerations as follows. Angiotensin-converting enzyme (ACE) inhibition lengthens survival in mice with autosomal recessive Alport syndrome and in dogs with X-linked Alport syndrome. ${ }^{910}$ When ACE inhibition in Alport mice is begun before the onset of proteinuria the duration of survival is doubled, a therapeutic result that thus far has not been exceeded by any other intervention. ACE inhibition started after the onset of proteinuria also improves survival in Alport mice, to a lesser but still significant degree. The effect of ramipril on survival was superior to that of candesartan in a head-to-head comparison. ${ }^{11}$

Analysis of retrospective data collected by the European Alport Registry indicates that ACE inhibitor therapy initiated while glomerular filtration rate is still normal delays end-stage renal disease by years. ${ }^{12,13}$ This effect has also been shown in pairs of affected brothers discordant for ACE inhibitor therapy. ${ }^{12} \mathrm{ACE}$ inhibition, angiotensin receptor blockade, and aldosterone inhibition have been shown to reduce proteinuria in children with Alport syndrome, in both uncontrolled and controlled studies. ${ }^{14-17}$ The effect of losartan on proteinuria was greater than the effect of amlodipine. ${ }^{17} \mathrm{As}$ shown in Effect of Strict Blood Pressure Control and ACE Inhibition on the Progression of CRF in Pediatric Patients, ACE inhibitors can be used safely in children with chronic kidney disease at doses that achieve suppression of urinary protein excretion. ${ }^{18,19}$ RAAS antagonists, especially ACE inhibitors, are relatively inexpensive and widely available. In theory, any child with Alport syndrome anywhere in the world should be able to receive treatment with an ACE inhibitor. This cannot be said for certain other treatments, for example, stem cell therapy that have shown promise in murine Alport syndrome, ${ }^{20-24}$ or for novel proprietary agents.

At the present time, our ability to assess the effect of angiotensin inhibition (or any other therapy) on progression of Alport nephropathy in individual patients is limited. Because microalbuminuria and proteinuria precede the onset of declining glomerular filtration rate by years, the effect of early intervention cannot be measured by assessing glomerular filtration rate. Reduction in albuminuria and proteinuria is an encouraging result, but not necessarily definitive. It has yet to be established that reduction in proteinuria in patients with Alport syndrome is predictive of delay in onset of end-stage renal disease; it is possible that angiotensin blockade exerts a protective effect even in the absence of reduction in proteinuria. A randomized placebo-controlled trial of ramipril therapy in Alport patients with stage 1 and stage 2 disease is underway in Europe (see NCT01485978, clinicaltrials.gov).

In males with Alport syndrome, glomerular filtration rate is inversely correlated with interstitial fibrosis. ${ }^{5}$ Biomarkers of renal interstitial fibrosis may be useful in monitoring the efficacy of angiotensin blockade or any other intervention. A search for useful biomarkers in patients with Alport syndrome is underway in several laboratories (see NCT01705132, clinicaltrials.gov).

\section{What does the future hold?}

While the ultimate goal of treatment for Alport syndrome, ie, a cure achieved by correction of the genetic defect, is still a distant hope, innovative therapeutic approaches that may augment or replace current treatment can be anticipated in the relatively near future. Several recent developments will facilitate trials of novel therapies. First, patient advocacy groups have been formed to educate and connect Alport 
Table 4 Patient advocacy groups and registries for Alport syndrome

\begin{tabular}{|c|c|}
\hline Patient advocacy groups & URL \\
\hline Alport Syndrome Foundation & alportsyndrome.org \\
\hline Alport Foundation of Australia & alport.org.au \\
\hline $\begin{array}{l}\text { Association pour l'Information et la Recherche } \\
\text { sur les maladies Rénales Génétiques (AIRG) }\end{array}$ & airg-france.fr \\
\hline Action for Alport's Campaign & kidneyresearchuk.org \\
\hline Registries & \\
\hline $\begin{array}{l}\text { Alport Syndrome Treatments and Outcomes } \\
\text { Registry (ASTOR) }\end{array}$ & alportregistry.org \\
\hline European Alport Registry & alport.de \\
\hline
\end{tabular}

families and raise funds for support of research, and second, large patient registries have been established in North America and Europe (Table 4). Lastly, pharmaceutical firms have become interested in developing treatments for rare diseases like Alport syndrome. Together, these developments have created a real potential for significant advances in the management of Alport syndrome.

\section{Disclosure}

The author reports no conflict of interest in this work.

\section{References}

1. Savige J, Gregory M, Gross O, Kashtan C, Ding J, Flinter F. Expert guidelines for the management of Alport syndrome and thin basement membrane nephropathy. J Am Soc Nephrol. 2013;24:364-375.

2. Kruegel J, Rubel D, Gross O. Alport syndrome - insights from basic and clinical research. Nat Rev Nephrol. 2013;9:170-178.

3. Jais JP, Knebelmann B, Giatras I, et al. X-linked Alport syndrome: natural history in 195 families and genotype-phenotype correlations in males. J Am Soc Nephrol. 2000;11:649-657.

4. Jais JP, Knebelmann B, Giatras I, et al. X-linked Alport syndrome: natural history and genotype-phenotype correlations in girls and women belonging to to 195 families: a "European Community Alport Syndrome Concerted Action" study. J Am Soc Nephrol. 2003;14:2603-2610.

5. Kashtan CE, Gubler MC, Sisson-Ross S, Mauer M. Chronology of renal scarring in males with Alport syndrome. Pediatr Nephrol. 1998;12:269-274

6. Kashtan CE. Familial hematuria. Pediatr Nephrol. 2009;24:1951-1958.

7. Kashtan CE. Alport syndrome and thin basement membrane nephropathy. In: Geary DF, Schaefer F, editors. Comprehensive Pediatric Nephrology. Philadephia, PA: Mosby Elsevier; 2008.
8. Kashtan CE, Ding J, Gregory M, et al. Clinical practice recommendations for the treatment of Alport syndrome: a statement of the Alport Syndrome Research Collaborative. Pediatr Nephrol. 2013;28:5-11.

9. Grodecki KM, Gains MJ, Baumal R, et al. Treatment of X-linked hereditary nephritis in Samoyed dogs with angiotensin converting enzyme inhibitor. J Comp Pathol. 1997;117:209-225.

10. Gross O, Beirowski B, Koepke ML, et al. Preemptive ramipril therapy delays renal failure and reduces renal fibrosis in COL4A3-knockout mice with Alport syndrome. Kidney Int. 2003;63:438-446.

11. Gross O, Schulze-Lohoff E, Koepke ML, et al. Antifibrotic, nephroprotective potential of ACE inhibitor vs AT1 antagonist in a murine model of renal fibrosis. Nephrol Dial Transplant. 2004;19:1716-1723.

12. Gross $\mathrm{O}$, Licht $\mathrm{C}$, Anders $\mathrm{H}$, et al. Early angiotensin-converting enzyme inhibition in Alport syndrome delays renal failure and improves life expectancy. Kidney Int. 2012;81:494-501.

13. Temme J, Peters F, Lange K, et al. Incidence of renal failure and nephroprotection by RAAS inhibition in heterozygous carriers of $\mathrm{X}$-chromosomal and autosomal recessive Alport mutations. Kidney Int. 2012;81:779-783.

14. Kaito H, Nozu K, Iijima K, et al. The effect of aldosterone blockade in patients with Alport syndrome. Pediatr Nephrol. 2006;21: 1824-1829.

15. Proesmans W, Knockaert H, Trouet D. Enalapril in paediatric patients with Alport syndrome: 2 years' experience. Eur J Pediatr. 2000;159: 430-433.

16. Proesmans W, Van Dyck M. Enalapril in children with Alport syndrome. Pediatr Nephrol. 2004;19:271-275.

17. Webb NJ, Lam C, Shahinfar S, et al. Efficacy and safety of losartan in children with Alport sydnrome - results from a subgroup analysis of a prospective, randomized placebo- or amlodipine-controlled trial. Nephrol Dial Transplant. 2011;28:2521-2526.

18. Wuhl E, Mehls O, Schaefer F. Antihypertensive and antiproteinuric efficacy of ramipril in children with chronic renal failure. Kidney Int. 2004;66:768-776.

19. Wuhl E, Trivelli A, Picca S, et al. Strict blood-pressure control and progression of renal failure in children. $N$ Engl J Med. 2009;361: $1639-1650$.

20. Floege J, Kunter U, Weber M, Gross O. Bone marrow transplantation rescues Alport mice. Nephrol Dial Transplant. 2006;21:2721-2723.

21. Lebleu V, Sugimoto H, Mundel TM, et al. Stem cell therapies benefit Alport syndrome. J Am Soc Nephrol. 2009;20:2359-2370.

22. Ninichuk V, Gross O, Segerer S, et al. Multipotent mesenchymal stem cells reduce interstitial fibrosis but do not delay progression of chronic kidney disease in collagen 4A3-deficient mice. Kidney Int. 2006;70:121-129.

23. Prodromidi EI, Poulsom R, Jeffery R, et al. Bone marrow-derived cells contribute to podocyte regeneration and amelioration of renal disease in a mouse model of Alport syndrome. Stem Cells. 2006;24:2448-2455.

24. Sugimoto H, Mundel TM, Sund M, Xie L, Cosgrove D, Kalluri R. Bone-marrow-derived stem cells repair basement membrane collagen defects and reverse genetic kidney disease. Proc Natl Acad Sci U S A. 2006;103:7321-7326.
Pediatric Health, Medicine and Therapeutics

\section{Publish your work in this journal}

Pediatric Health, Medicine and Therapeutics is an international, peerreviewed, open access journal publishing original research, reports, editorials, reviews and commentaries. All aspects of health maintenance preventative measures and disease treatment interventions are addressed within the journal. Practitioners from all disciplines are invited to submit

\section{Dovepress}

their work as well as healthcare researchers and patient support groups. The manuscript management system is completely online and includes a very quick and fair peer-review system. Visit http://www.dovepress.com/ testimonials.php to read real quotes from published authors 